\title{
COMPARATIVE STUDY OF THE EFFECT OF SUPEROXIDE SOLUTION VERSUS CHLORHEXIDINE GLUCONATE SOLUTION IN SURGICAL WOUND DRESSING
}

\author{
BHUPINDER SINGH WALIA, PANKAJ DUGG*, KESHAV PALIWAL, SANJEEV SHARMA, ASHWANI KUMAR
}

Department of Surgery, Government Medical College, Amritsar, Punjab, India. Email: dr_dugg@hotmail.com

Received: 01 December 2021, Revised and Accepted: 10 January 2021

\begin{abstract}
Objective: The objective of the study is to compare the effect of superoxide solution (SOD) and chlorhexidine gluconate on wound healing.

Methods: Hundred patients with different types of wounds were recruited in this study and randomized to two groups: Group A- SOD group and Group B- Chlorhexidine group. Observations were made regarding type of wounds, reduction of edema, culture of wounds, improvement, cure rates, and hospital stay.
\end{abstract}

Results: Although there were no significant difference in the reduction of edema and swelling of wound in both groups, the cure rates were statistically better with SOD $(\mathrm{p}=0.001)$ and hospital stay was also less with the use of SOD $(\mathrm{p}=0.006)$.

Conclusion: SOD treated case showed less morbidity, with more improvement, and more cure rate compared to chlorhexidine solution with statistically significant p-value. However, further research into the use of SOD and the cytotoxic nature of chlorhexidine in the treatment of various wounds is required.

Keywords: Wound healing, Superoxides, Chlorhexidine gluconate.

(C) 2022 The Authors. Published by Innovare Academic Sciences Pvt Ltd. This is an open access article under the CC BY license (http://creativecommons.org/ licenses/by/4.0/) DOI: http://dx.doi.org/10.22159/ajpcr.2022v15i2.43733. Journal homepage: https://innovareacademics.in/journals/index.php/ajpcr

\section{INTRODUCTION}

Wound healing is affected by various growth factors such as epidermal growth factor, Interleukins, tumor necrosis factor, and platelet derived growth factor [1]. In addition to, these there are various factors that influence wound healing such as age, nutritional, obesity, diabetes, immunosuppressants, and infections.

In general, dirty wounds have a higher risk of infection and have a poly-microbial etiology, and standard treatment includes cleansing and debridement. There has always been a search for an ideal antiseptic that is rapidly lethal to all forms of bacteria and their spores and capable of bactericidal properties for a prolonged period with no ill effect on host tissues. Superoxidized solutions have shown to be both safe and efficient as a wound care product that moistens, lubricates, debrides, and reduces the microbial load of various types of lesions $[2,3]$.

Another antiseptic is chlorhexidine, which is characterized as being a strong base with cationic properties. It is available in both freebase and stable salt forms, with a white or yellowish appearance $[4,5]$. Chlorhexidine gluconate (aqueous or alcoholic) is an antiseptic thought to be effective against a wide range of Gram-positive and Gram-negative bacteria, yeasts, and some viruses [6].

This study compares both antiseptic agents, namely, superoxide solution (SOD) and chlorhexidine gluconate in wound healing.

\section{METHODS}

The study was conducted on 100 patients presented to the surgery department from November 2019 to November 2020. Approval from the institutional ethics committee and informed consent from patients was taken.

Cases were divided into two groups:

- Study group (A) which comprises 50 cases, the dressing and topical management, was done with SOD
- Study group (B) which comprises of 50 cases, the dressing and topical management, was done with chlorhexidine gluconate solution.

The solution was applied to the wounds through different methods like washing, sprinkling and gauze dressing. At the time of admission, a printed pro forma was filled recording age, sex, date of admission, duration of wound, symptoms, and physical findings. The results of various investigations such as: Complete blood counts, blood sugar, blood urea, serum creatinine, serum proteins (total serum protein, DSP), serum electrolytes ( $\mathrm{Na}+\mathrm{K}+\mathrm{Ca}++$ ), serum markers (HIV, Hep $\mathrm{B}$, and Hep $\mathrm{C}$ ), liver function tests (Serum bilirubin, serum glutamic oxaloacetic transaminase, serum glutamic pyruvic transaminase, and serum alkaline phosphatase), and radiological investigations wherever indicated were also recorded. The antibiotics were given in both cases empirically and after culture and sensitivity wherever indicated.

Observations were made during dressing and examination of the wound was done on days $1,5,9,12,18$, and 21 and findings noted in the pro forma. The efficacy evaluation was based on the appearance of the wound, presence or absence of odor, discharge, periwound edema, slough, granulation tissue, duration of antibiotic cover, and duration of hospital stay. The patients were also assessed for local and systemic reactions based on symptoms such as irritation, eruption, edema, redness, and anaphylaxis during and after the application of antiseptic solution.

\section{Inclusion criteria}

The following criteria were included in the study:

- All cases of traumatic wounds

- All wounds of elective surgery such as cholecystectomy, hernia repair, cyst excision, genitourinary cases, commando operation with flap repair, and surgery for various malignancies

- All wounds of inflammatory organ pathology because of any etiological factors such as appendicitis, cholecystitis, abscesses, and Fournier's gangrene

- All cases of burns, diabetic foot ulcer, carbuncles, and venous stasis ulcer 
- All cases of hollow viscous perforation admitted in various surgical wards.

\section{Statistical analysis}

Data were summarized as Mean \pm SD (standard deviation). Association between independent and dependent variables was done by Chi-square $\left(\chi^{2}\right)$ test. $\mathrm{p}<0.05$ was considered statistically significant. Analysis was performed with SPSS software (Windows version 21.0)

\section{RESULTS}

Different patients of different age groups were studied; youngest patient was of 1.5 years and the oldest of 75 years. The mean age was 41.05 years (Table 1 )

All types of wounds are categorized in four main types according to Centers for Disease Control and Prevention wound classification system. Clean case category includes aseptic surgical incision; clean contaminated cases include surgical operations that transact the gastrointestinal, genitourinary or tracheobronchial system without gross spillage; contaminated category of cases includes cases where there were gross spillage and road traffic accidents and operations for peritonitis; and dirty case category includes wounds contaminated by purulent material or dirty discharge from a hollow viscus. Both comparing groups have an insignificant distribution of cases with $\mathrm{p}=0.10$ (Table 2).

Periwound edema is a hallmark of inflammation. In this study, edema was noted at baseline at the time of presentation and its reduction on subsequent days. On day 5 , there was $25 \%$ reduction in Group A and $24 \%$ reduction in Group B. On day 9 , there was $51 \%$ reduction in edema noted in Group A and 46\% in Group B. On day 12, there was $72 \%$ reduction in edema in Group A and 68\% reduction in Group B. On day18, there was 84\% reduction in swelling in Group A and 81\% in Group B. On day 21, there was $90 \%$ mean reduction in swelling in Group A and 85\% in Group B. Although insignificant as p value suggests on observed day, decrease in edema noted in Group A was consistently less compared to Group B (Table 3).

Table 1: Age distribution

\begin{tabular}{|c|c|c|c|c|c|c|}
\hline \multirow[t]{2}{*}{ Age group (years) } & \multicolumn{2}{|c|}{ Group A } & \multicolumn{2}{|c|}{ Group B } & \multicolumn{2}{|c|}{ Total } \\
\hline & $\mathbf{n}$ & $\%$ & $\mathbf{n}$ & $\%$ & $\mathbf{n}$ & $\%$ \\
\hline$<10$ & 4 & 8 & 2 & 4 & 6 & 6 \\
\hline $11-20$ & 4 & 8 & 2 & 4 & 6 & 6 \\
\hline $21-30$ & 7 & 14 & 9 & 18 & 16 & 16 \\
\hline $31-40$ & 12 & 24 & 14 & 28 & 26 & 26 \\
\hline $41-50$ & 9 & 18 & 8 & 14 & 17 & 17 \\
\hline $51-60$ & 6 & 12 & 10 & 20 & 16 & 16 \\
\hline $61-70$ & 6 & 12 & 4 & 8 & 10 & 10 \\
\hline$>70$ & 2 & 4 & 1 & 2 & 3 & 3 \\
\hline Total & 50 & 100 & 50 & 100 & 100 & 100 \\
\hline Mean age & \multicolumn{2}{|c|}{$40.76 \pm 18.85$} & \multicolumn{2}{|c|}{$41.35 \pm 15.94$} & \multicolumn{2}{|c|}{$41.05 \pm 17.37$} \\
\hline p-value & \multicolumn{2}{|c|}{0.866} & \multirow{2}{*}{\multicolumn{2}{|c|}{1.5}} & & \\
\hline Minimum age & \multirow{2}{*}{\multicolumn{2}{|c|}{$\begin{array}{l}4 \\
75\end{array}$}} & & & \multicolumn{2}{|l|}{1.5} \\
\hline Maximum age & & & \multicolumn{2}{|l|}{72} & \multicolumn{2}{|l|}{75} \\
\hline
\end{tabular}

Table 2: Type of wound

\begin{tabular}{|c|c|c|c|c|c|c|}
\hline \multirow[t]{2}{*}{ Type of wounds } & \multicolumn{2}{|c|}{ Group A } & \multicolumn{2}{|c|}{ Group B } & \multicolumn{2}{|c|}{ Total } \\
\hline & $\mathbf{n}$ & $\%$ & $\mathbf{n}$ & $\%$ & $\mathbf{n}$ & $\%$ \\
\hline Clean wounds & 7 & 14 & 14 & 28 & 21 & 21 \\
\hline Clean contaminated & 15 & 30 & 6 & 12 & 21 & 21 \\
\hline Contaminated & 13 & 26 & 14 & 28 & 27 & 27 \\
\hline Dirty wounds & 15 & 30 & 16 & 32 & 31 & 31 \\
\hline Total & 50 & 100 & 50 & 100 & 100 & 100 \\
\hline
\end{tabular}

$\mathrm{X}^{2}: 6.260, \mathrm{df}: 3, \mathrm{P}=0.100$
There was decrease in positivity of culture with time in both groups. However, no significant difference was observed in between the groups (Table 4).

Improvement in surgical wounds was observed as the appearance of healthy granulation tissue, less slough, free from infection, less discharge, and good vascularity. In this study, Group A shown improvement in $34 \%$ cases compared to $16 \%$ cases in Group B, which was significant $(\mathrm{p}=0.037)$ (Table 5$)$.

Cure rate observed in Group A was $96 \%$ compared to $72 \%$ in Group B up to day 21. Remaining cases took longer time to heal. Group A observed cure in 48 cases compared to 36 cases in Group B in an observation time of 21 days $(p=0.001)$ (Table 6).

Hospital stay in different categories of wounds observed as depicted above in the table. In each category, Group A had lesser duration of hospital stay compared to Group B, making SOD a good antiseptic (Table 7).

\section{DISCUSSION}

Disinfection of wounds with the use of locally used antiseptic solutions is important, although multimode therapy is the basis of wound healing. An ideal antiseptic is one that is rapidly lethal to all forms of bacteria and their spores, capable of bactericidal activity for prolonged

Table 3: Percentage decrease in swelling/edema

\begin{tabular}{lllllll}
\hline \multirow{2}{*}{$\begin{array}{l}\text { Day of } \\
\text { examination }\end{array}$} & \multicolumn{2}{l}{ Group A } & & \multicolumn{2}{c}{ Group B } & p-value \\
\cline { 2 - 3 } & Mean & SD & & Mean & SD & \\
\hline 1 & 0.000 & 0.000 & & 0.000 & 0.000 & \\
5 & 25.800 & 10.755 & & 24.600 & 10.093 & 0.566 \\
9 & 51.500 & 21.577 & & 46.800 & 19.451 & 0.255 \\
12 & 72.050 & 20.891 & & 68.100 & 23.253 & 0.392 \\
18 & 84.170 & 16.453 & & 81.280 & 20.905 & 0.503 \\
21 & 90.000 & 13.484 & 85.380 & 17.431 & 0.310 \\
\hline
\end{tabular}

Table 4: Cultures obtained on various days

\begin{tabular}{|c|c|c|c|c|}
\hline \multirow{2}{*}{$\begin{array}{l}\text { Day of taking } \\
\text { culture }\end{array}$} & \multicolumn{2}{|l|}{ Group A } & \multicolumn{2}{|l|}{ Group B } \\
\hline & Negative & Positive & Negative & Positive \\
\hline 5 & 21 & 19 & 23 & 15 \\
\hline 9 & 26 & 14 & 25 & 13 \\
\hline 12 & 31 & 9 & 26 & 12 \\
\hline 18 & 34 & 6 & 31 & 8 \\
\hline 21 & 38 & 2 & 35 & 3 \\
\hline
\end{tabular}

Table 5: Improvement in wounds

\begin{tabular}{|c|c|c|c|c|c|c|}
\hline \multirow[t]{2}{*}{ Improvement } & \multicolumn{2}{|c|}{ Group A } & \multicolumn{2}{|c|}{ Group B } & \multicolumn{2}{|c|}{ Total } \\
\hline & No & $\%$ & No & $\%$ & No & $\%$ \\
\hline Present & 17 & 34 & 8 & 16 & 25 & 25 \\
\hline Absent & 33 & 66 & 42 & 84 & 75 & 75 \\
\hline Total & 50 & 100 & 50 & 100 & 100 & 100 \\
\hline
\end{tabular}

$\mathrm{X}^{2}: 4.32$, df: $1, P=0.037$

Table 6: Cure rate

\begin{tabular}{|c|c|c|c|c|c|c|}
\hline \multirow[t]{2}{*}{ Cure } & \multicolumn{2}{|c|}{ Group A } & \multicolumn{2}{|c|}{ Group B } & \multicolumn{2}{|c|}{ Total } \\
\hline & No & $\%$ & No & $\%$ & No & $\%$ \\
\hline Present & 48 & 96 & 36 & 72 & 84 & 84 \\
\hline Absent & 2 & 4 & 14 & 28 & 16 & 16 \\
\hline Total & 50 & 100 & 50 & 100 & 100 & 100 \\
\hline
\end{tabular}


periods, has no injurious effect on wound healing tissues, easy to apply and remove, has a wide spectrum of activity and absence of acquired bacterial resistance.

The present study was conducted on various aspects of wound healing with SOD and chlorhexidine gluconate. Observations were made in terms of type of wound; decrease in periwound edema; organisms cultured on various observation days; mean hospital stay in various categories; and cure rates.

In our study, the age groups were comparable in both groups with the maximum age in Group A was 75 years and the minimum was 4 years and in Group B it was 72 and 1.5 years, respectively, (Table 1). Mean age was $41.05 \pm 17.37$. Sridhar et al. in his study on diabetic wounds reported the mean age of patients to be $56.4 \pm 18.6$ years with male predominance [7]

The types of wounds treated were almost comparable in both groups (Table 2). In the current study, wounds managed by SOD and

Table 7: Duration of hospital stay according to the type of wound

\begin{tabular}{lllllll}
\hline \multirow{2}{*}{ Type of wounds } & \multicolumn{3}{l}{ Hospital stay } & \multicolumn{3}{c}{ p-value } \\
\cline { 2 - 3 } & \multicolumn{2}{l}{ Group A } & & \multicolumn{2}{c}{ Group B } & \\
\cline { 2 - 3 } & Mean & SD & & Mean & SD & \\
\hline Clean & 5.71 & 3.30 & & 7.42 & 4.21 & 0.361 \\
Clean Contaminated & 8.66 & 1.86 & & 9.60 & 5.57 & 0.697 \\
Contaminated & 11.27 & 5.33 & & 16.84 & 16.72 & 0.302 \\
Dirty & 5.00 & 2.42 & & 7.00 & 6.73 & 0.290 \\
Total & 7.29 & 4.95 & & 11.06 & 8.23 & 0.006 \\
\hline
\end{tabular}

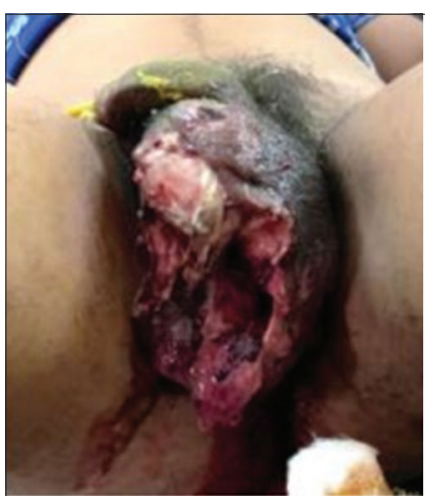

On presentation

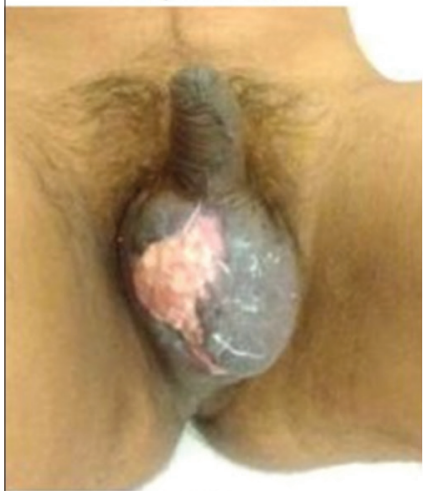

$18^{\text {th }}$ day

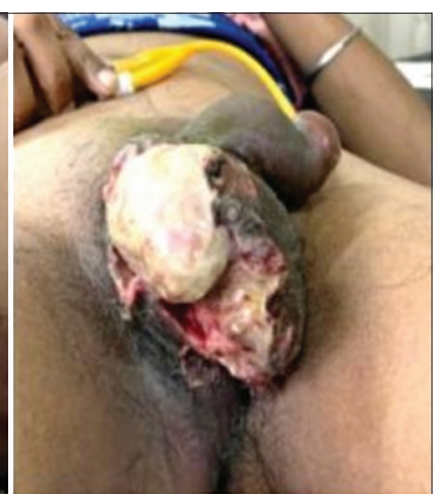

$5^{\text {th }}$ day

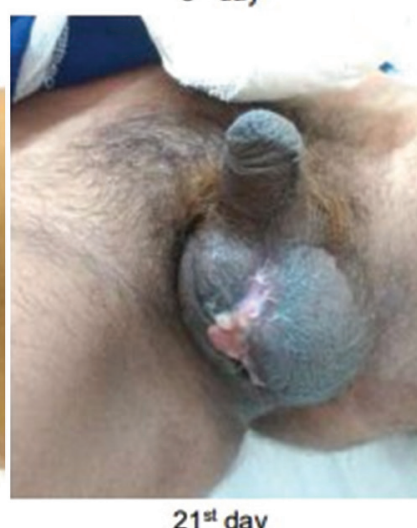

A CASE OF FOURNIER GANGRENE AT DIFFERENT TIME INTERVAL SHOWING HEALING (GROUP A) chlorhexidine solution both showed a significant reduction in edema and discharge in acute and chronic wounds. Although both groups show significant reduction in periwound edema, difference between two groups was not statistically significant $(p>0.05)$ (Table 3).

Gandhi et al., 2016, in his study to compare the effectiveness of chlorhexidine dressing with traditional gauze dressing found that there is decreased incidence of fever and frequency of infection in chlorhexidine dressings [8]. The frequency with which the dressing had to be changed was also reduced. The hospital stay period and postoperative pain experienced by the patients in whom chlorhexidine dressing was used also reduced and showed faster rates of wound healing.

In the current study, wound swabs sent for culture and sensitivity yields microorganisms, but majority of swabs (44\%) were found to be sterile in observation up to $5^{\text {th }}$ day. At the $12^{\text {th }}$ day of observation, only $26 \%$ discharges were positive for the organism and at the $21^{\text {st }}$ day of observation, only five cases were positive for organisms (Table 4). Both solutions were effective in decreasing the bioburden of infected wounds. SOD treated group shows less culture positivity onward the $12^{\text {th }}$ day of observation, empirical antimicrobial therapy was given in every case before sensitivity report and according to the report after culture. However, there is not much difference in improvement rates in both groups (Table 5), the cure rates with SOD were statistically better compared to chlorhexidine group (Table 6 and Figs. 1-2).In a study conducted at the Hospital Civil de Guadalajara in Mexico in 2004-2005 with superficial, partial, deep partial, and full thickness burns, the study group was treated with SOS and was compared retrospectively with 58 similar burns at the institution which had been treated with silver solutions/ointments (control group). In this trial, only six patients received antibiotics in the SOD group versus 56 in the control group [9].

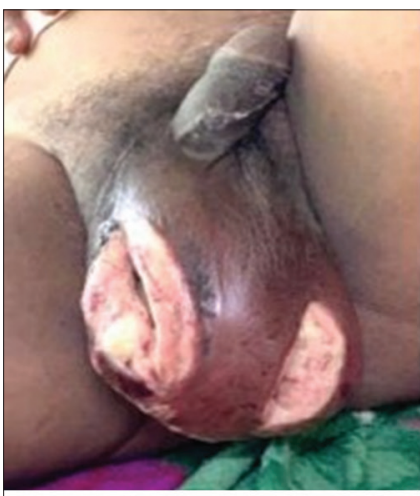

At presentation

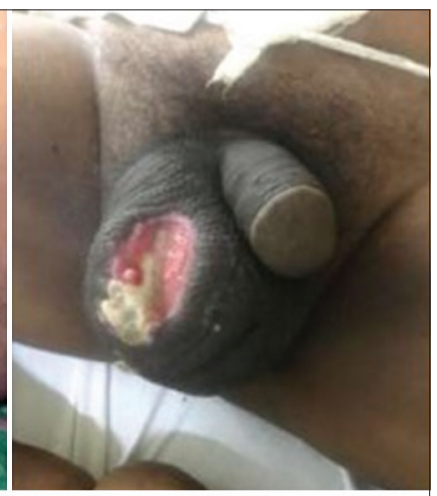

$9^{\text {th }}$ day

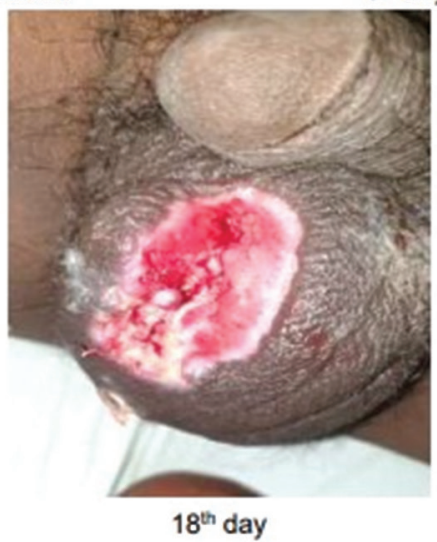

A CASE OF FOURNIER GANGRENE AT DIFFERENT TIME INTERVAL SHOWING HEALING (GROUP B)

Fig. 2: Group B case of Fournier's gangrene 
In the study of Abdel-Sayed et al., the implication of chlorhexidine solution in burn wound care established its large spectrum of action and its role in bacterial resistant infections. They also concluded that the lower concentrations of chlorhexidine are as efficient as higher concentrations [10]. In the current study, patients of burns treated with SOD showed early recovery with less eschar formation and better granulation and rapid healing. Furthermore, irritation and pain while applying SOD was less when compared to chlorhexidine gluconate solution. The appearance of granulation tissue was healthy with evidence of better microcirculation.

Duration of hospital stay is a good indicator of antisepsis and wound health. In the current study, the mean hospital stay was $9.49 \pm 6.12$ days. Cases treated with SOD showed less hospital stay $(7.29 \pm 4.95$ days) compared to cases treated with chlorhexidine solution (11.06 \pm 8.23 days) with statically significant values (Table 7). Mean hospital stay of individual wound category was calculated and observed less duration of hospital stay in each category in the SOD group making it more efficient compared to chlorhexidine gluconate. Similar results were shown in the study conducted by Miranda et al. where hospital stay was reduced by $50 \%$ in the SOD group versus control group [9].

In vitro study of Liu et al. showed the cytotoxic effect of chlorhexidine gluconate on human fibroblasts, myoblasts, and osteoblasts, reducing cell survival and delaying the healing time. Although, it was an in vitro study and further in vivo studies are required to examine the safety of chlorhexidine gluconate [11].

Gutierrez in his study to explore various applications of superoxidized solutions concluded that the moistening effects and minimum toxicity found with the use of this superoxidized solution made it a good choice for wound case management and that this non-antibiotic technology appears to offer a broad new paradigm for the prevention and treatment of acute and chronic wounds [12].

\section{CONCLUSION}

The results of this study therefore appear to show more favorable results for SOD than for chlorhexidine solution. However, the results are statistically significant, the strength of evidence depends upon the study design. The results of this study justify further research into the use of SOD and the cytotoxic nature of chlorhexidine in the treatment of various wounds. It is important to ensure that possible sources of bias in further studies are excluded, for example, by randomization of patients to treatment and by blinded assessment of outcomes.

\section{AUTHOR CONTRIBUTION}

All authors have substantially contributed in

1. The conception or design of the work; or the acquisition, analysis, or interpretation of data for the work

2. Drafting the work or revising it critically for important intellectual content

3. Final approval of the version to be published

\section{REFERENCES}

1. Kapur V, Marwaha AK. Evaluation of effect and comparison of superoxidised solution (Superoxide solution) $\mathrm{v} / \mathrm{s}$ povidone iodine (betadine). Ind J Surg 2011;73:48-53.

2. Sekiya S, Ohmori K, Harii K. Treatment of infectious skin defects or ulcers with electrolyzed strong acid aqueous solution. Artif Organs 1997;21:32-8

3. Tanaka H, Hirakata Y, Kaku M, Yoshida R, Takemura H, Mizukane R, et al. Antimicrobial activity of superoxidized water. J Hosp Inf 1996;34:43-9.

4. McDonnell G, Russell AD. Antiseptics and disinfectants: Activity, action, and resistance. Clin Microbiol Rev 1999;12:147-79.

5. Krautheim AB, Jermann TH, Bircher AJ. Chlorhexidine anaphylaxis: Case report and review of the literature. Contact Dermat 2004;50:113-6.

6. Boyce J, Chartier Y, Chraiti M, Cookson B, Damani N, Dharan S. WHO Guidelines on Hand Hygiene in Health Care. Geneva: World Health Organization. 2009.

7. Sridhar S, Nanjappa N. Microbiological and clinical response of superoxidized solution versus povidone iodine in the management of lower limb ulcers. Natl J Physiol Pharm Pharmacol 2017;7:1074-80.

8. Gandhi JA, Shinde PH, Awasthi AA, Digarse R, Kawle AP. Comparative study of chlorhexidine dressings versus simple gauze dressings in midline laparotomy wound. Int J Res Med Sci 2016;4:4272.

9. Altamirano AM, Preciado DM, Velarde TJ. Treatment of $2^{\text {nd }}$ and $3^{\text {rd }}$ Degree Burns in 64 Pediatric Patietns Without Routine Antibiotics using New "Super-oxidized Solution Technology" Texas Surgical Society Congress. San Antonio, Tx. $1^{\text {st }}-3^{\text {rd }}$ April, 2005 and European Burns Association Meeting 2005. Estoril Portugal; 2005.

10. Abdel-Sayed P, Tornay D, Hirt-Burri N, Roessingh AD, Raffoul W, Applegate LA. Implications of chlorhexidine use in burn units for wound healing. Burns 2020;46:1150-6.

11. Liu JX, Werner J, Kirsch T, Zuckerman JD, Virk MS. Cytotoxicity evaluation of chlorhexidine gluconate on human fibroblasts, myoblasts, and osteoblasts. J Bone Joint Infect 2018;3:165.

12. Gutiérrez AA. The science behind stable super-oxidized water. Wounds 2006;18:7. 